\title{
Small-Signal Modeling of SiGe HBTs Using Direct Parameter-Extraction Method
}

\author{
Han-Yu Chen, Kun-Ming Chen, Guo-Wei Huang, Member, IEEE, and Chun-Yen Chang, Life Fellow, IEEE
}

\begin{abstract}
A simple and accurate parameter-extraction method of a high-frequency small-signal SiGe heterojunction bipolar transistor model is proposed in this paper. It was found that, without taking the intrinsic circuit elements into account, the conductance of the substrate network will be underestimated, while the susceptance of the substrate network will be overestimated. Therefore, a new extraction technique of the substrate-network parameters was developed, which has taken the intrinsic circuit elements into consideration. Transforming the intrinsic equivalent circuit into its common-collector configuration, all the intrinsic circuit elements are extracted directly from the measured $S$-parameters without any numerical optimization. Two formulas used to determine the intrinsic base resistance are presented, which is followed by an accuracy-improvement procedure to achieve a better accuracy of the extraction results. Simplified formulas to determine the base-emitter resistance, base-emitter capacitance, transconductance, and excess phase delay are also presented. The proposed method is validated with SiGe HBTs fabricated with a $0.35-\mu \mathrm{m}$ BiCMOS technology from 1 to $30 \mathrm{GHz}$. The agreements between the measured and modeled data are excellent in the desired frequency range over a wide range of bias points.
\end{abstract}

Index Terms-Heterojunction bipolar transistor (HBT), parameter extraction, SiGe, small-signal model, substrate network.

\section{INTRODUCTION}

$\mathbf{S}$ iGe HETEROJUNCTION bipolar transistors (HBTs) were first demonstrated in the late 1980s [1] and quickly became popular in wireless communication applications, in the form of wireless transceiver circuits [2], [3], due to the higher performance than the Si devices and higher integration level than the III-V devices. An accurate extraction method for a small-signal equivalent circuit of SiGe HBTs is vital for designing a circuit, evaluating the process technology, and optimizing device performance. Recently, several papers have reported small-signal equivalent-circuit parameter-extraction methods for SiGe HBTs [4]-[7], in which the substrate effects have been taken into account. Most of these extraction techniques for the substrate network were based on the use of the frequency behavior of $\left(Y_{22}+Y_{21}\right)$. However, we found out that the feedback signal through the internal circuit elements makes $\left(Y_{22}+Y_{21}\right)$ deviate from the admittance of the substrate network, and the modeling results may have no physical meaning if the parameter extraction of substrate networks is directly performed on the mea-

Manuscript received January 5, 2006; revised May 30, 2006. The review of this paper was arranged by Editor C. McAndrew.

H.-Y. Chen and C.-Y. Chang are with the Department of Electronic Engineering and Institute of Electronics, National Chiao Tung University, Hsinchu 300, Taiwan, R.O.C.

K.-M. Chen and G.-W. Huang are with the National Nano Device Laboratories, Hsinchu 300, Taiwan, R.O.C. (e-mail: kmchen@mail.ndl.org.tw).

Digital Object Identifier 10.1109/TED.2006.881055 sured $\left(Y_{22}+Y_{21}\right)$. Therefore, to extract the substrate-network parameters, the intrinsic circuit elements of SiGe HBTs should be determined first.

In this paper, we present a simple and accurate parameterextraction method of a high-frequency small-signal SiGe HBTs model and an improved extraction method of substrate-network parameters. The equivalent circuit adopted in this paper is based on the hybrid- $\pi$ topology which is popular in commercial circuit simulators such as vertical bipolar inter-company model (VBIC), most exquisite transistor model (MEXTRAM), and high-current model (HICUM). Based on the algorithm proposed in [8] and [9], this paper expands the essence of the extraction technique in hybrid- $\pi$-topology HBT small-signal modeling. Since the intrinsic base resistance is involved in the extraction of some intrinsic circuit parameters, an accurate extraction of the resistance is important to avoid any accumulated errors. Two formulas used to determine the intrinsic base resistance are presented, which is followed by an accuracyimprovement procedure to achieve a better accuracy of the extraction results. All the circuit elements are extracted directly from a measured $S$-parameter without any preknowledge or numerical optimization. In the extraction of substrate-network parameters, we extract the intrinsic circuit parameters first to erase the influence of a feedback signal through the internal circuit elements. The proposed extraction procedure was experimentally verified on a SiGe HBT in the frequency range of $1-30 \mathrm{GHz}[10]$.

\section{EXTRACTION OF EXTRINSIC ELEMENTS AND Substrate-Network Parameters}

Fig. 1 shows the small-signal equivalent circuit of a $\mathrm{SiGe}$ HBT under forward-active-mode operation. The model is based on the well-known hybrid- $\pi$ equivalent circuit with a threeelement substrate network adding a parallel RC block connected in series with the collector-substrate capacitance [11]. The equivalent circuit is divided into two parts, with the inner part (in the dashed box) containing the bias-dependent intrinsic elements and the outer part with the mostly bias-independent extrinsic elements.

To extract the equivalent-circuit parameters, pad parasitics are carefully removed from measured $S$-parameters through a de-embedding procedure using an "open" test pattern. Some remaining parasitics not removed in the de-embedding procedure, such as parasitic capacitances, pad inductances, and series resistances, are relatively small, but lead eventually to errors in extracting the intrinsic elements. Thus, their values should be determined carefully. After removing the residual parasitics, the 


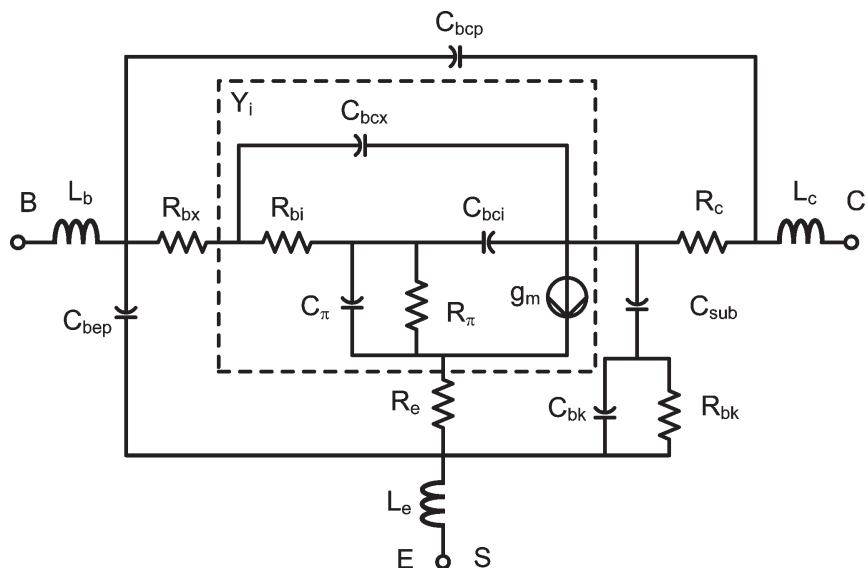

Fig. 1. Small-signal equivalent-circuit model for a SiGe HBT in the forwardactive region.

extraction of substrate-network parameters and, subsequently, the intrinsic parameters can then be performed.

As reported in [12]-[14], the extraction of parasitic elements is made by biasing the device first in forward operation (high base current $\left.I_{B}\right)$ in order to extract the parasitic resistances ( $R_{\mathrm{bx}}, R_{c}$, and $R_{e}$ ) and inductances $\left(L_{b}, L_{c}\right.$, and $\left.L_{e}\right)$. The device is then biased in the cutoff operation mode (the collector voltage $V_{\mathrm{CE}}=0$ and the reverse and/or low forward base voltage $V_{\mathrm{BE}}$ ), permitting the extraction of the parasitic capacitances $\left(C_{\mathrm{bep}}\right.$ and $\left.C_{\mathrm{bcp}}\right)$.

Under the bias conditions ( $V_{\mathrm{BE}}=0$ and forward and/or low reverse collector voltage), the substrate-network parameters can be estimated from the $Y$-parameters analysis of the equivalent circuit shown in Fig. 1. After removing the extrinsic inductances, parasitic capacitances, extrinsic base resistance, and collector resistance, the equivalent circuit of Fig. 1 is reduced to that of Fig. 2(a).

In this paper, the substrate network $Y_{\text {sub }}$ is composed of the substrate-collector depletion capacitance $C_{\text {sub }}$, effective substrate resistance $R_{\mathrm{bk}}$, and effective bulk capacitance $C_{\mathrm{bk}}$, accounting for the Si dielectric behavior. For simplicity, the influence of emitter resistance $R_{e}$ has been neglected where the approximation is valid for $\left(\omega R_{e} C_{\pi}\right)^{2} \ll 1$. We transform the intrinsic part of the device equivalent circuit $\left(R_{\mathrm{bi}}, C_{\pi}\right.$, and $C_{\mathrm{bci}}$ ) using the well-known $\mathrm{T} \leftrightarrow \Pi$ transformations shown in detail in the right side of Fig. 2(b). After the two-port matrix operations, the admittance parameters of $\left[Y_{k}\right]$, which is shown in Fig. 2(b), is obtained as

$$
\begin{aligned}
& Y_{11, k}=j w C_{\mathrm{bcx}}+\frac{j w\left(C_{\mathrm{bci}}+C_{\pi}\right)}{1+j w R_{\mathrm{bi}}\left(C_{\mathrm{bci}}+C_{\pi}\right)} \\
& Y_{12, k}=Y_{21, k}=-j w C_{\mathrm{bcx}}-\frac{j w C_{\mathrm{bci}}}{1+j w R_{\mathrm{bi}}\left(C_{\mathrm{bci}}+C_{\pi}\right)} \\
& Y_{22, k}=Y_{\mathrm{sub}}+j w C_{\mathrm{bcx}}+\frac{j w C_{\mathrm{bci}}\left(1+j w R_{\mathrm{bi}} C_{\pi}\right)}{1+j w R_{\mathrm{bi}}\left(C_{\mathrm{bci}}+C_{\pi}\right)}
\end{aligned}
$$

From (2) and (3), we can derive

$$
Y_{22, k}+Y_{21, k}=Y_{\text {sub }}+Y_{3}
$$



(a)
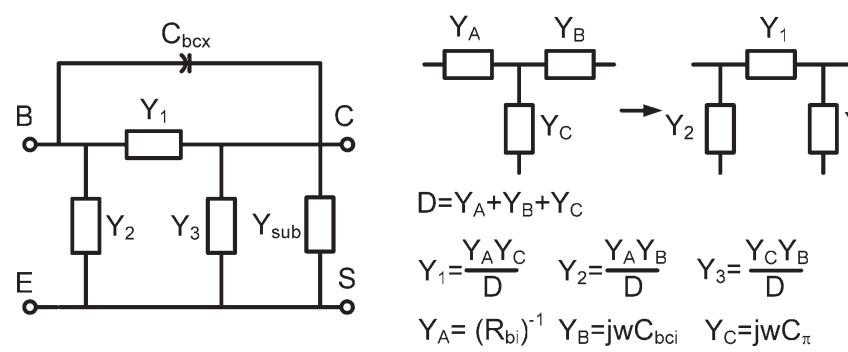

(b)

Fig. 2. (a) Small-signal equivalent-circuit model for a SiGe HBT biased at $V_{\mathrm{BE}}=0$ and forward and/or low reverse collector voltage after de-embedding the "open" dummy pad and removing the extrinsic inductances, extrinsic base resistance, and extrinsic collector resistance. (b) Application of the $\mathrm{T} \leftrightarrow \Pi$ transformation to the HBT device equivalent circuit shown in (a).

where

$$
\begin{aligned}
Y_{\mathrm{sub}}= & \frac{\omega^{2} R_{\mathrm{bk}} C_{\mathrm{sub}}^{2}}{1+\omega^{2} R_{\mathrm{bk}}^{2}\left(C_{\mathrm{bk}}+C_{\mathrm{sub}}\right)^{2}} \\
& +j \omega C_{\mathrm{sub}}\left(\frac{1+\omega^{2} R_{\mathrm{bk}}^{2} C_{\mathrm{bk}}\left(C_{\mathrm{bk}}+C_{\mathrm{sub}}\right)}{1+\omega^{2} R_{\mathrm{bk}}^{2}\left(C_{\mathrm{bk}}+C_{\mathrm{sub}}\right)^{2}}\right) \\
Y_{3}= & \frac{-\omega^{2} C_{\mathrm{bci}} C_{\pi} R_{\mathrm{bi}}}{1+\omega^{2} R_{\mathrm{bi}}^{2}\left(C_{\mathrm{bci}}+C_{\pi}\right)^{2}} \\
& +j \frac{\omega^{3} C_{\mathrm{bci}} C_{\pi}\left(C_{\mathrm{bci}}+C_{\pi}\right) R_{\mathrm{bi}}^{2}}{1+\omega^{2} R_{\mathrm{bi}}^{2}\left(C_{\mathrm{bci}}+C_{\pi}\right)^{2}} .
\end{aligned}
$$

From (4), it is clear that $\left(Y_{22, k}+Y_{21, k}\right)$ deviates from $Y_{\text {sub }}$ by an additional term $Y_{3}$, which is composed of the intrinsic circuit elements. If the extraction of substrate-network parameters is performed on $Y_{22, k}+Y_{21, k}$, the conductance of the substrate network will be underestimated, and the susceptance of the substrate network will be overestimated.

To extract the substrate-network parameters, $Y_{3}$ should be determined first. From (1) and (2), $R_{\mathrm{bi}}$ and $C_{\pi}$ can be obtained as

$$
\begin{aligned}
R_{\mathrm{bi}} & =\operatorname{Re}\left[\frac{1}{Y_{11, k}+Y_{12, k}}\right] \frac{\operatorname{Re}\left(Y_{11, k}+Y_{12, k}\right)}{\operatorname{Re}\left(Y_{11, k}\right)} \\
\omega C_{\pi} & =-\operatorname{Im}\left(\frac{1}{Y_{11, k}+Y_{12, k}}\right)^{-1} .
\end{aligned}
$$

As shown in Fig. 3(a), the $R_{\mathrm{bi}}$ extracted from (7) is nearly constant, and the $\omega C_{\pi}$ extracted from (8) is linear. We find 


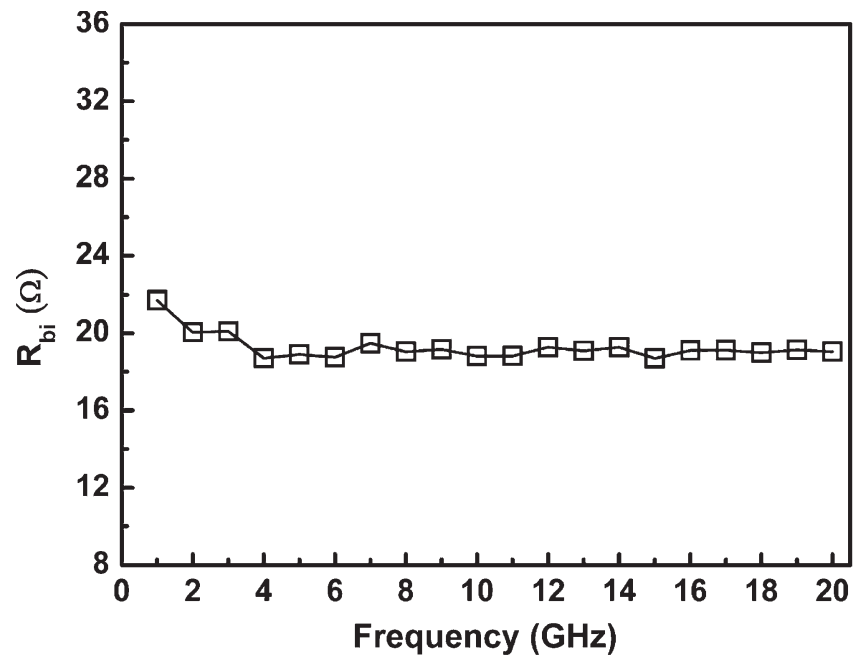

(a)

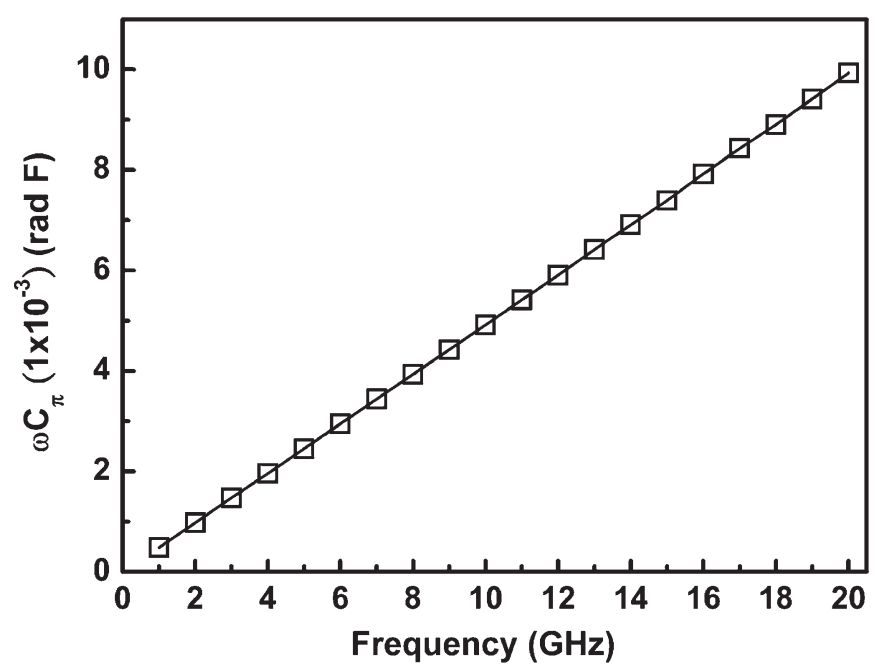

(b)

Fig. 3. Frequency dependences of the extracted (a) $R_{\mathrm{bi}}$ and (b) $\omega C_{\pi}$ for a SiGe HBT biased at $V_{\mathrm{BE}}=0 \mathrm{~V}$ and $V_{\mathrm{CE}}=3 \mathrm{~V}$.

$R_{\mathrm{bi}}=19.04 \Omega$ and $C_{\pi}=78.97 \mathrm{fF}$ at $V_{\mathrm{CE}}=3.0 \mathrm{~V}$, and $V_{\mathrm{BE}}=$ $0 \mathrm{~V}$ for the $3 \times 0.34 \times 8 \mu \mathrm{m}^{2} \mathrm{SiGe}$ HBT. In the low-frequency range, $\operatorname{Re}\left(Y_{11, k}\right)$ can be approximately rewritten as [15]

$$
\begin{aligned}
\operatorname{Re}\left(Y_{11, k}\right)= & \frac{\omega^{2} R_{\mathrm{bi}}\left(C_{\pi}+C_{\mathrm{bci}}\right)^{2}}{1+\omega^{2} R_{\mathrm{bi}}^{2}\left(C_{\pi}+C_{\mathrm{bci}}\right)^{2}} \\
& \left.\sim \omega^{2} R_{\mathrm{bi}}\left(C_{\pi}+C_{\mathrm{bci}}\right)^{2}\right|_{\text {at low frequency }}
\end{aligned}
$$

under the assumption, $\omega^{2} R_{\mathrm{bi}}^{2}\left(C_{\pi}+C_{\mathrm{bci}}\right)^{2} \ll 1$. A typical result of (9) at $V_{\mathrm{CE}}=3.0 \mathrm{~V}$ and $V_{\mathrm{BE}}=0 \mathrm{~V}$ for a $3 \times 0.34 \times$ $8 \mu \mathrm{m}^{2}$ SiGe HBT is shown in Fig. 4, from which the slope is fitted as $1.393 \times 10^{-25}$. The intrinsic base-collector capacitance $C_{\mathrm{bci}}$ can be extracted as $6.553 \mathrm{fF}$ from $C_{\mathrm{bci}}=\beta^{0.5} R_{\mathrm{bi}}^{-0.5}-C_{\pi}$, where $\beta$ is the slope of $\operatorname{Re}\left(Y_{11, k}\right)$ versus $\omega^{2}$ plot. Substituting the extracted values of $R_{\mathrm{bi}}, C_{\pi}$, and $C_{\mathrm{bci}}$ to (6), $Y_{3}$ is obtained. From (4), $Y_{\text {sub }}$ is then obtained by removing $Y_{3}$ from $Y_{22, k}+$ $Y_{21, k}$. Since the accuracy of the extracted $C_{\mathrm{bci}}$ will strongly affect $Y_{\text {sub }}$, it is necessary to check the validation of the extracted values. In this paper, the $C_{\mathrm{bci}}$ is obtained from the calculation

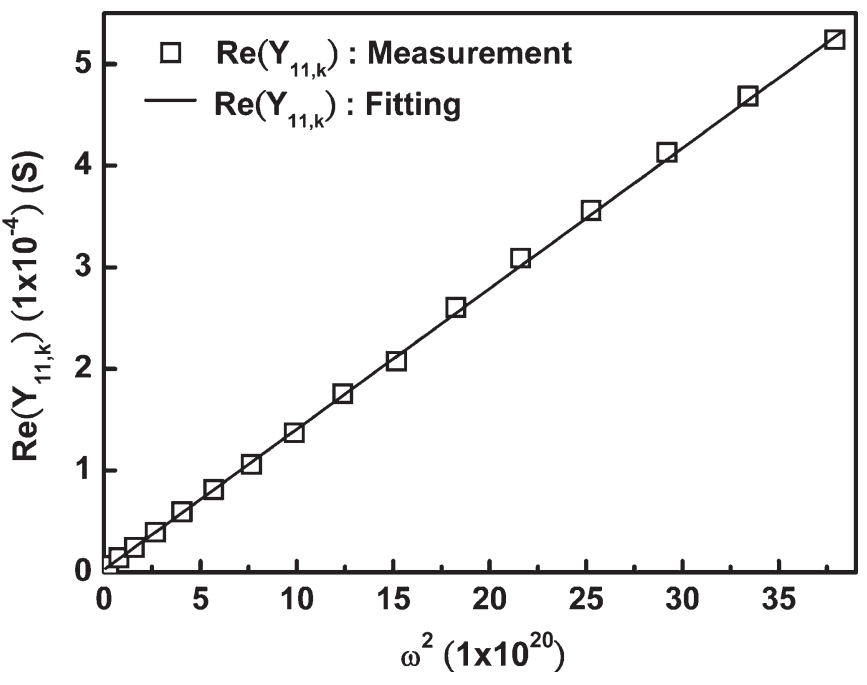

Fig. 4. Plot of $\operatorname{Re}\left(Y_{11, k}\right)$ versus $\omega^{2}$ for the calculation of $C_{\mathrm{bci}}$ for a $\mathrm{SiGe}$ HBT biased at $V_{\mathrm{BE}}=0 \mathrm{~V}$ and $V_{\mathrm{CE}}=3 \mathrm{~V}$.

of $R_{\mathrm{bi}}, C_{\pi}$, and $\beta$. The extracted $R_{\mathrm{bi}}$ is frequency independent, as shown in Fig. 3(a). The extracted $C_{\pi}$ is collector-voltage independent and is equal to $\operatorname{Im}\left(Y_{11}+Y_{12}\right) / \omega-C_{\text {bep }}$ at low frequency. Since $\operatorname{Re}\left(Y_{11, k}\right)$ under cutoff-mode operation has been widely used in [15]-[17], we believe $\beta$ can be extracted accurately. Therefore, the extracted $C_{\mathrm{bci}}$ is reliable.

Fig. 5 shows the comparison between the measured $\left(Y_{22, k}+\right.$ $\left.Y_{21, k}\right)$ and $Y_{\text {sub }}$ for a $3 \times 0.34 \times 8 \mu \mathrm{m}^{2}$ SiGe HBT biased at $V_{\mathrm{BE}}=0$ and $V_{\mathrm{CE}}=0$ and $3 \mathrm{~V}$. Due to the internal feedback signal through $Y_{3}, \operatorname{Re}\left(Y_{22, k}+Y_{21, k}\right)$ and $\operatorname{Im}\left(Y_{22, k}+Y_{21, k}\right) / \omega$ show a deviation from $\operatorname{Re}\left(Y_{\text {sub }}\right)$ and $\operatorname{Im}\left(Y_{\text {sub }}\right) / \omega$ as the operation frequency is beyond 5 and $10 \mathrm{GHz}$, respectively. As shown in Fig. 6, a negative value of $\operatorname{Re}\left(Y_{22, k}+Y_{21, k}\right)$ can also be found in the SiGe HBTs with an emitter width larger than $0.5 \mu \mathrm{m}$. This indicates that $Y_{3}$ (or intrinsic circuit elements) indeed affects the measured $\left(Y_{22, k}+Y_{21, k}\right)$. If the extraction of the substrate-network parameters is directly performed on $Y_{22, k}+Y_{21, k}$, a negative effective substrate resistance will be extracted, and the modeling results of a substrate network may contribute error in the extraction of the intrinsic circuit elements.

After obtaining $Y_{\mathrm{sub}}$ from (4), $C_{\mathrm{sub}}, R_{\mathrm{bk}}$, and $C_{\mathrm{bk}}$ can be determined by the previously reported method [5], [15]. Fig. 7 shows the collector-voltage dependence of the extracted substrate-network parameters. The solid line shown in Fig. 7 is the empirical fitting for $C_{\mathrm{sub}}$ by the equation $C_{\mathrm{sub}}=C_{\mathrm{sub}, p}+$ $C_{\text {sub }, 0}\left(1-V_{\mathrm{ce}} / V_{\mathrm{sci}}\right)^{-m_{\mathrm{sc}}}$, and the fitting value are $10.83 \mathrm{fF}$, $9.54 \mathrm{fF}, 0.702 \mathrm{~V}$, and 0.47 for $C_{\mathrm{sub}, p}, C_{\mathrm{sub}, 0}, V_{\mathrm{sci}}$, and $\mathrm{m}_{\mathrm{sc}}$, respectively.

To explain the bias dependence of $R_{\mathrm{bk}}$ and $C_{\mathrm{bk}}$, a simple $n^{+}-p$ junction shown in Fig. 8 is used to represent the collector-substrate junction of SiGe HBTs. When the collector voltage increases, the collector-substrate depletion width $W_{\text {sub }}$ increases due to an increasing reverse bias across the junction. Therefore, the width of the neutral region $W_{\mathrm{bk}}$ reduces, leading to the reduction of $R_{\mathrm{bk}}$ and the increase of $C_{\mathrm{bk}}$ [11]. After extraction of the substrate-network parameters, $Y_{\text {sub }}$ is deembedded through the standard two-port operation. 


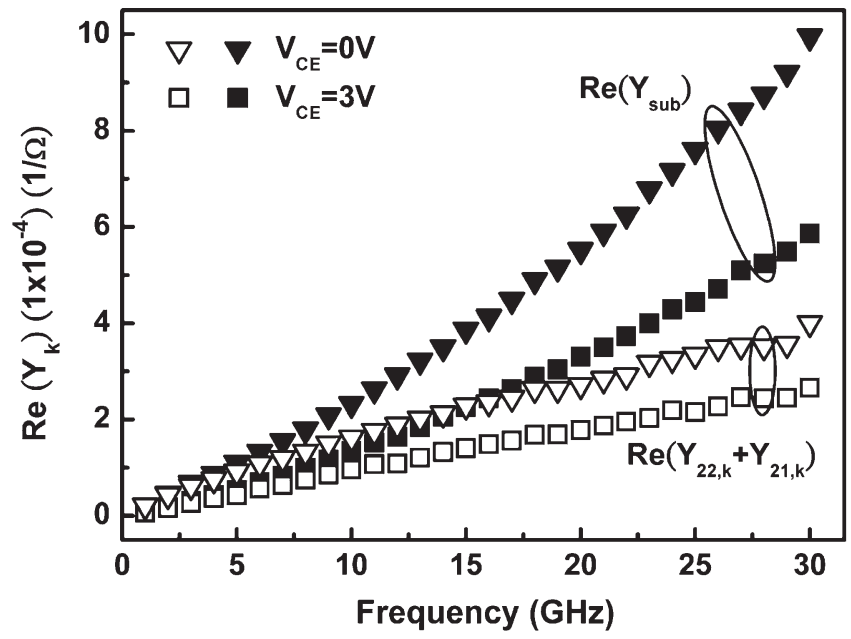

(a)

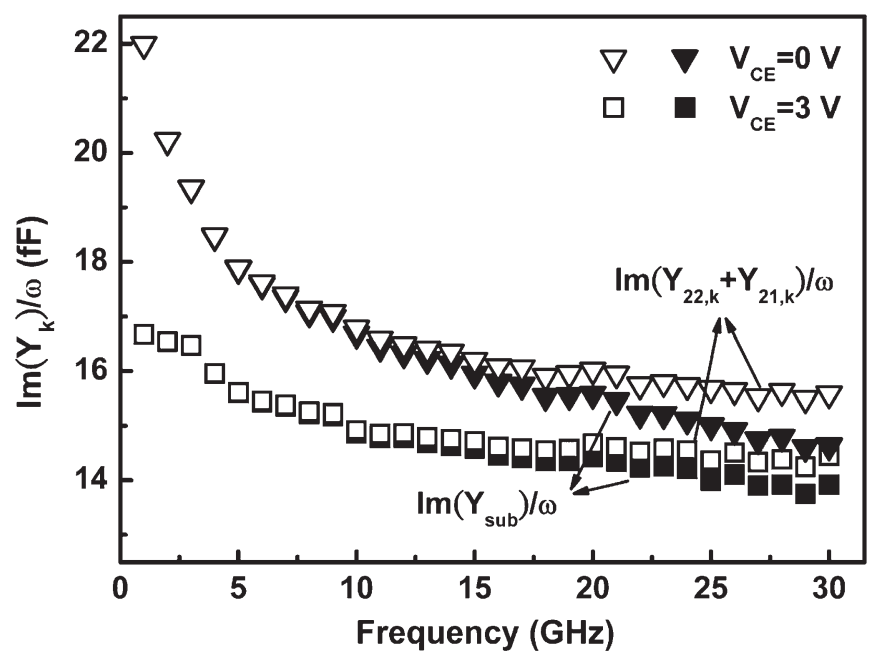

(b)

Fig. 5. Comparison between $Y_{\text {sub }}$ and $Y_{22, k}+Y_{21, k}$ for a SiGe HBT biased at $V_{\mathrm{BE}}=0 \mathrm{~V}$ and $V_{\mathrm{CE}}=0$ and $3 \mathrm{~V}$. (a) $\operatorname{Re}\left(Y_{\mathrm{sub}}\right)$ and $\operatorname{Re}\left(Y_{22, k}+Y_{21, k}\right)$. (b) $\operatorname{Im}\left(Y_{\text {sub }}\right)$ and $\operatorname{Im}\left(Y_{22, k}+Y_{21, k}\right)$.

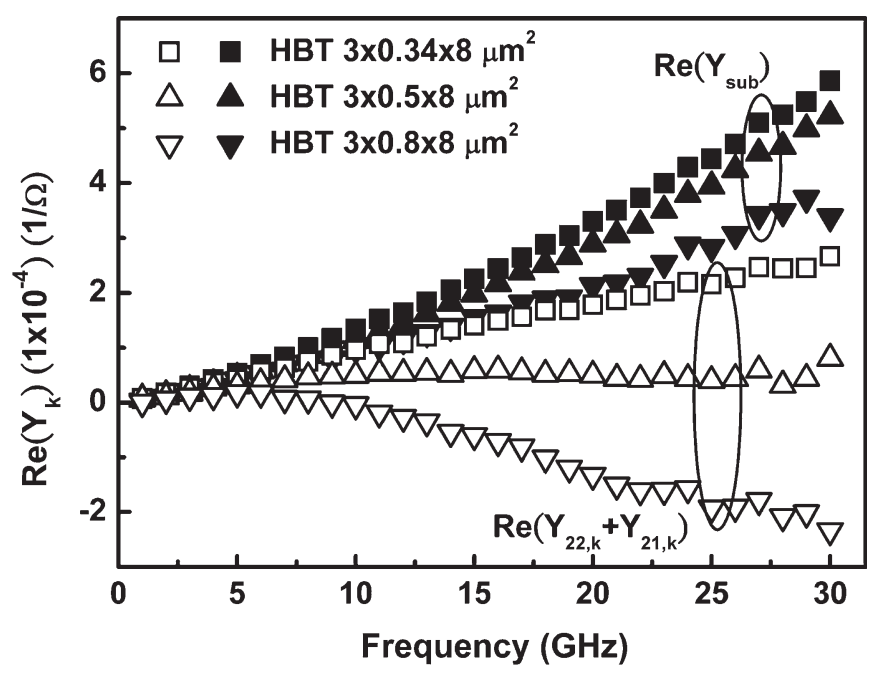

Fig. 6. Frequency dependence of the extracted $\operatorname{Re}\left(Y_{\text {sub }}\right)$ and $\operatorname{Re}\left(Y_{22, k}+\right.$ $\left.Y_{21, k}\right)$ for three SiGe HBTs with different emitter width $(0.34,0.5$, and $0.8 \mu \mathrm{m}$ ) biased at $V_{\mathrm{BE}}=0 \mathrm{~V}$ and $V_{\mathrm{CE}}=3 \mathrm{~V}$.

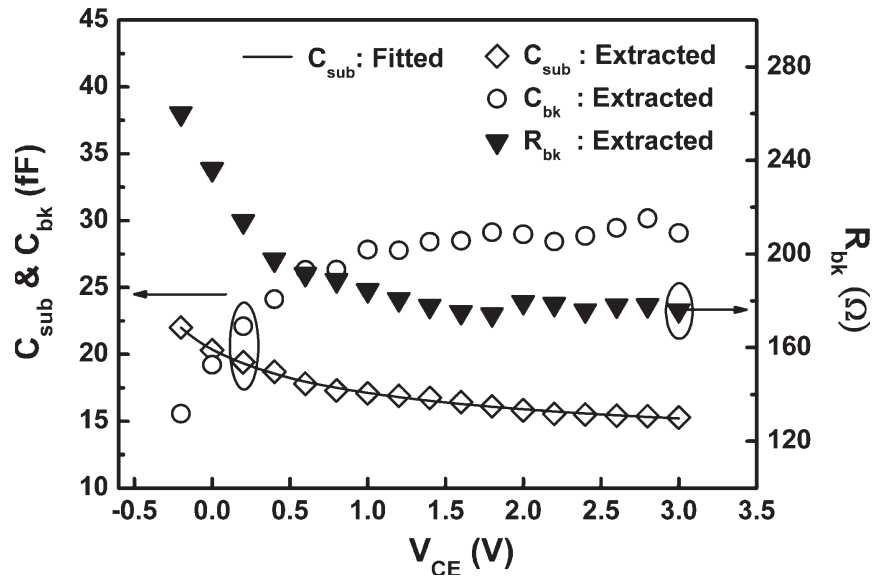

Fig. 7. Collector-voltage dependence of the extracted $C_{\mathrm{sub}}, R_{\mathrm{bk}}$, and $C_{\mathrm{bk}}$ for a $\mathrm{SiGe} \mathrm{HBT}$ biased at $V_{\mathrm{BE}}=0 \mathrm{~V}$. Solid line gives the empirical fitting for $C_{\text {sub. }}$.

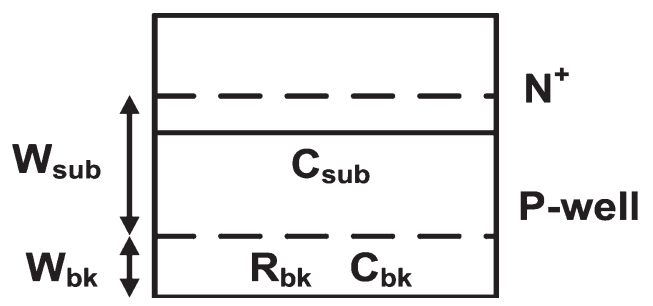

Fig. 8. Cross-sectional view of a simple $\mathrm{n}^{+}$-p junction.

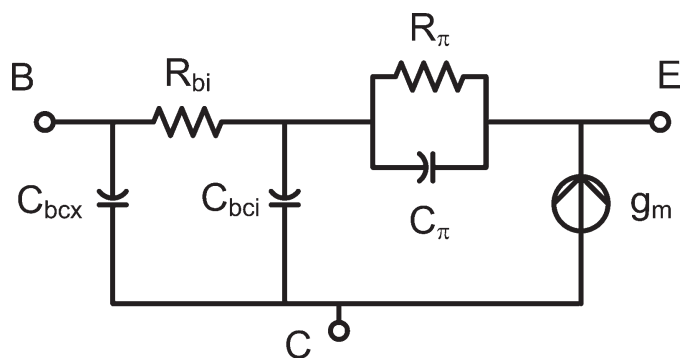

Fig. 9. Small-signal equivalent-circuit model of intrinsic SiGe HBT in a common-collector configuration.

\section{Extraction of Intrinsic Circuit Elements}

Usually, the admittance parameters of the intrinsic HBT in common-emitter configuration $\left[Y_{n}\right]$ are used to extract intrinsic circuit elements [18], [19]. A much simpler set of equations is obtained if the equivalent circuit of the intrinsic HBT is transformed to its common-collector configuration, as shown in Fig. 9 [8], [9]. After the two-port matrix operations, we arrive at the following $\mathrm{ABCD}$-parameters $\left[A_{c}\right]$ of the intrinsic HBT

$$
\begin{aligned}
A_{c, 11}= & 1+R_{\mathrm{bi}} Y_{\mathrm{bc}} \\
A_{c, 12}= & \frac{1}{g_{m}+Y_{\pi}}\left(1+R_{\mathrm{bi}} Y_{\mathrm{bc}}+R_{\mathrm{bi}} Y_{\pi}\right) \\
A_{c, 21}= & Y_{\mathrm{bc}}+Y_{\mathrm{ex}}+R_{\mathrm{bi}} Y_{\mathrm{ex}} Y_{\mathrm{bc}} \\
A_{c, 22}= & \frac{1}{g_{m}+Y_{\pi}} \\
& \times\left[Y_{\mathrm{ex}}\left(1+R_{\mathrm{bi}} Y_{\mathrm{bc}}+R_{\mathrm{bi}} Y_{\pi}\right)+Y_{\mathrm{bc}}+Y_{\pi}\right]
\end{aligned}
$$


where $g_{m}=g_{m 0} \exp (-j \omega \tau), \quad Y_{\pi}=1 / R_{\pi}+j \omega C_{\pi}, \quad Y_{\mathrm{bc}}=$ $j \omega C_{\mathrm{bci}}$, and $Y_{\mathrm{ex}}=j \omega C_{\mathrm{bcx}}$. The advantage of transforming the intrinsic circuit into its common-collector configuration is that some circuit parameters such as $g_{m}$ and $Y_{\pi}$ only appear in $A_{c, 12}$ and $A_{c, 22}$, and this facilitates the extraction of some intrinsic circuit parameters.

\section{A. Extraction of $R_{\mathrm{bi}}, C_{\mathrm{bci}}, C_{\pi}$, and $C_{\mathrm{bcx}}$}

From (11) and (13), the well-known ABCD-parameter formulation for the extraction of intrinsic base resistance $R_{\mathrm{bi}}$, which is given in [8], is shown as

$$
\begin{aligned}
& \operatorname{Re}\left(\frac{A_{c, 12}}{A_{c, 22}}\right) \\
& =\frac{\omega^{2} R_{\mathrm{bi}}\left(C_{\mathrm{bci}}+C_{\pi}\right)^{2}}{\omega^{4} R_{\mathrm{bi}}^{2} C_{\mathrm{ex}}^{2}\left(C_{\mathrm{bci}}+C_{\pi}\right)^{2}+\omega^{2}\left(C_{\mathrm{bci}}+C_{\pi}+C_{\mathrm{ex}}\right)^{2}} .
\end{aligned}
$$

Since the $\omega^{4}$ term in the denominator is much smaller than the $\omega^{2}$ term at the middle- to high-frequency ranges, (14) is simplified to

$$
\begin{aligned}
\operatorname{Re} & \left(\frac{A_{c, 12}}{A_{c, 22}}\right) \\
& \left.\sim R_{\mathrm{bi}} \frac{\left(C_{\mathrm{bci}}+C_{\pi}\right)^{2}}{\left(C_{\mathrm{bci}}+C_{\pi}+C_{\mathrm{ex}}\right)^{2}}\right|_{\text {at middle to high frequency }}
\end{aligned}
$$

which set up the lower limit of $R_{\mathrm{bi}}$. Another equation for the extraction of $R_{\mathrm{bi}}$ can be obtained from (10) to (13)

$$
\begin{aligned}
\operatorname{Re}\left(\frac{A_{c, 12}}{\left|A_{c}\right|}\right) & =R_{\mathrm{bi}}\left(1+\frac{C_{\mathrm{bci}}}{C_{\pi}}\right)+\frac{1}{\omega^{2} R_{\pi} C_{\pi}^{2}} \\
& \left.\sim R_{\mathrm{bi}}\left(1+\frac{C_{\mathrm{bci}}}{C_{\pi}}\right)\right|_{\text {at middle to high frequency }}
\end{aligned}
$$

where $\left|A_{c}\right|$ denotes $\left(A_{c, 11} A_{c, 22}-A_{c, 12} A_{c, 21}\right)$. It is clear that (16) set up the upper limit of $R_{\mathrm{bi}}$. Typical results of (15) and (16) are shown in Fig. 10. We find the lower and upper limits of $R_{\mathrm{bi}}$ as 18.15 and $16.35 \Omega$, respectively, at $I_{B}=7.915 \mu \mathrm{A}$, $I_{C}=1.332 \mathrm{~mA}$, and $V_{\mathrm{CE}}=3.0 \mathrm{~V}$ for the $3 \times 0.34 \times 8 \mu \mathrm{m}^{2}$ SiGe HBT. The $R_{\mathrm{bi}}$ estimated from (15) is then applied to obtain the intrinsic base-collector capacitance $C_{\mathrm{bci}}$ through the following equation

$$
\operatorname{Im}\left(A_{c, 11}\right)=\omega R_{\mathrm{bi}} C_{\mathrm{bci}} .
$$

The value of $R_{\mathrm{bi}} C_{\mathrm{bci}}$ is calculated from the slope of (17) when plotted versus the angular frequency $\omega$, as shown in Fig. 11. It should be noted that the adopted $R_{\mathrm{bi}}$ from (15) only serve as an initial value, and it will be corrected in the accuracyimprovement procedure.

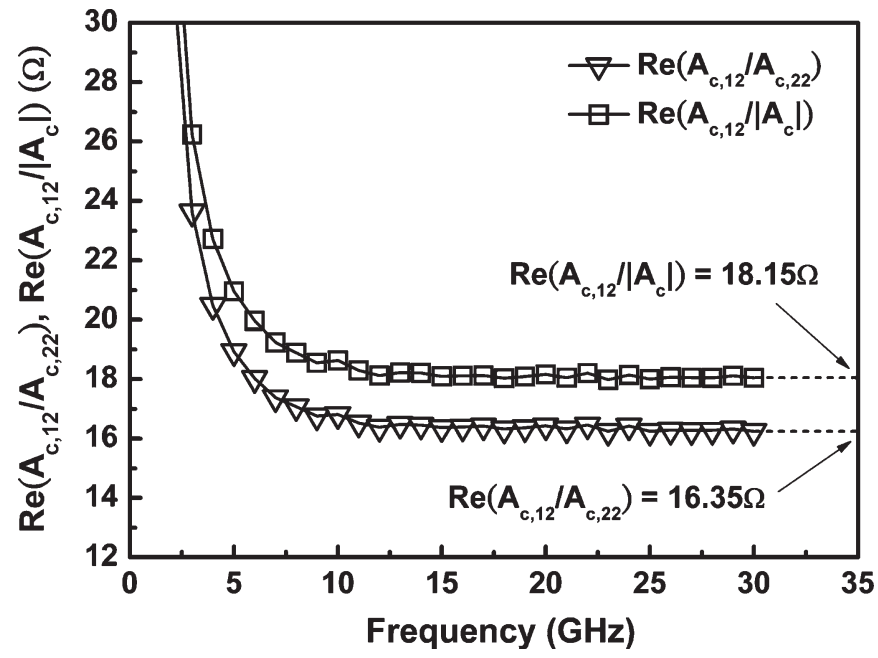

Fig. 10. Plot of $\operatorname{Re}\left(A_{c, 12} / A_{c, 22}\right)$ and $\operatorname{Re}\left(A_{c, 12} /\left|A_{c}\right|\right)$ versus frequency. $V_{\mathrm{BE}}=0.83 \mathrm{~V}, V_{\mathrm{CE}}=3 \mathrm{~V}, I_{C}=1.333 \mathrm{~mA}$, and $I_{B}=7.915 \mu \mathrm{A}$.

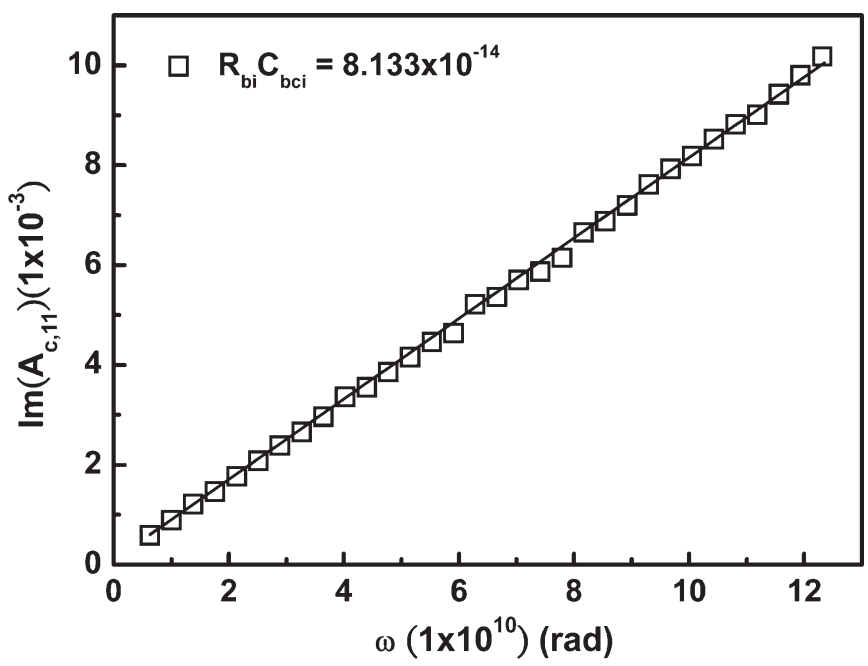

Fig. 11. Plot of $\operatorname{Im}\left(A_{c, 11}\right)$ versus $\omega . V_{\mathrm{BE}}=0.83 \mathrm{~V}, V_{\mathrm{CE}}=3 \mathrm{~V}, I_{C}=$ $1.333 \mathrm{~mA}$, and $I_{B}=7.915 \mu \mathrm{A}$.

By examining (10) to (13), we can extract the intrinsic base-emitter capacitance $C_{\pi}$ through the following equation

$$
\begin{aligned}
\operatorname{Im}\left(\frac{A_{c, 12}}{\left|A_{c}\right|}\right) & =\frac{\omega R_{\pi} C_{\mathrm{bci}} R_{\mathrm{bi}}-\omega R_{\pi}^{2} C_{\pi}}{1+\left(\omega R_{\pi} C_{\pi}\right)^{2}} \\
& \left.\sim \frac{-1}{\omega C_{\pi}}\left(1-\frac{R_{\mathrm{bi}}}{R_{\pi}} \frac{C_{\mathrm{bci}}}{C_{\pi}}\right)\right|_{\text {at middle to high frequency }} \\
& \left.\sim \frac{-1}{\omega C_{\pi}}\right|_{\text {at middle to high frequency. }}
\end{aligned}
$$

The value of $C_{\pi}$ is calculated from the slope of (18) when plotted versus $1 / \omega$, as shown in Fig. 12.

To extract the extrinsic base-collector capacitance $C_{\mathrm{bcx}}$, we obtain the following equation by inspecting (10) and (12)

$$
\operatorname{Im}\left(\frac{A_{c, 11}}{A_{c, 21}}\right)=\frac{\omega^{3} R_{\mathrm{bi}}^{3} C_{\mathrm{bci}}^{2} C_{\mathrm{bcx}}-\omega\left(C_{\mathrm{bci}}+C_{\mathrm{bcx}}\right)}{\omega^{4}\left(R_{\mathrm{bi}} C_{\mathrm{bci}} C_{\mathrm{bcx}}\right)^{2}+\omega^{2}\left(C_{\mathrm{bci}}+C_{\mathrm{bcx}}\right)^{2}}
$$

In the low- to middle-frequency ranges, the $\omega^{4}$ term in the denominator is much smaller than the $\omega^{2}$ term. Also, the $\omega^{3}$ 


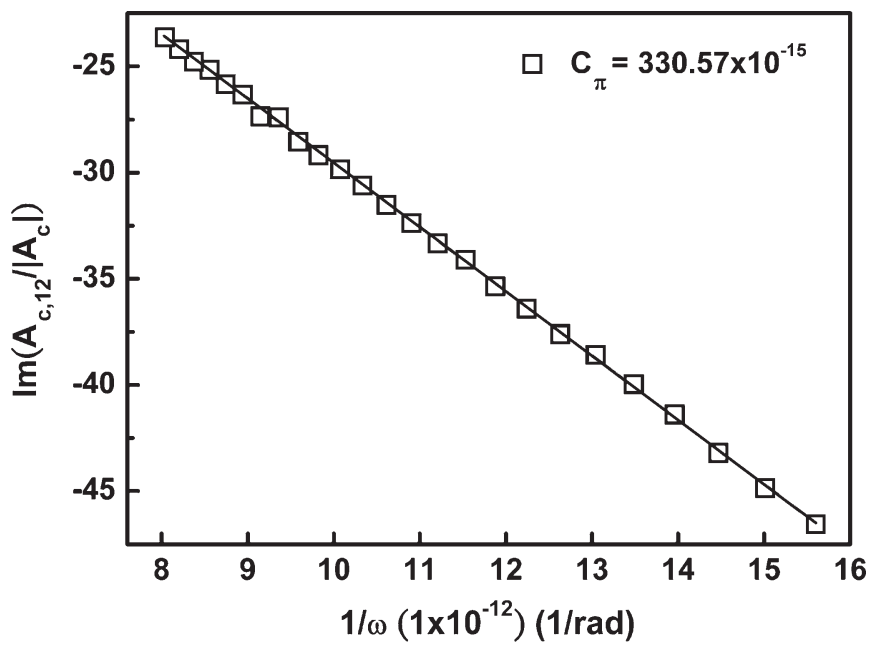

Fig. 12. Plot of $\operatorname{Im}\left(A_{c, 12} /\left|A_{c}\right|\right)$ versus $1 / \omega . V_{\mathrm{BE}}=0.83 \mathrm{~V}, V_{\mathrm{CE}}=3 \mathrm{~V}$, $I_{C}=1.333 \mathrm{~mA}$, and $I_{B}=7.915 \mu \mathrm{A}$.

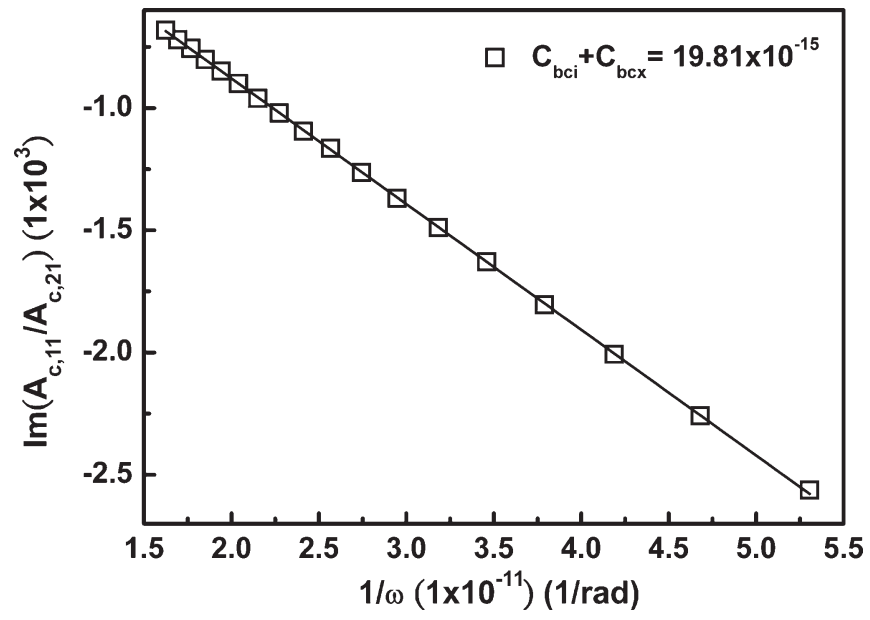

Fig. 13. Plot of $\operatorname{Im}\left(A_{c, 11} / A_{c, 21}\right)$ versus $1 / \omega . V_{\mathrm{BE}}=0.83 \mathrm{~V}, V_{\mathrm{CE}}=3 \mathrm{~V}$, $I_{C}=1.333 \mathrm{~mA}$, and $I_{B}=7.915 \mu \mathrm{A}$.

term in the numerator is much smaller than the $\omega$ term. Thus, (19) is simplified to

$$
\left.\operatorname{Im}\left(\frac{A_{c, 11}}{A_{c, 21}}\right) \sim \frac{-1}{\omega\left(C_{\mathrm{bci}}+C_{\mathrm{bcx}}\right)}\right|_{\text {at }} \text { low to middle frequency. }
$$

The value of $C_{\mathrm{bci}}+C_{\mathrm{bcx}}$ is calculated from the slope of (20) when plotted versus $1 / \omega$, as shown in Fig. 13. Since the value of $C_{\mathrm{bci}}$ has been previously determined, $C_{\mathrm{bcx}}$ is obtained by subtracting $C_{\mathrm{bci}}+C_{\mathrm{bcx}}$ from $C_{\mathrm{bci}}$.

\section{B. Accuracy Improvement of $R_{\mathrm{bi}}, C_{\mathrm{bci}}$, and $C_{\mathrm{bcx}}$}

In (17) and (20), we found that $R_{\mathrm{bi}}$ plays a significant role on the accuracy of the extracted $C_{\mathrm{bci}}$ and, subsequently, the accuracy of the extracted $C_{\mathrm{bcx}}$. However, the estimated value of $R_{\mathrm{bi}}$ from (15) is lower than the real one. Thus, an accuracyimprovement procedure is necessary and is listed as follows.

1) As mentioned in Section III-A, the value of $R_{\mathrm{bi}}$ estimated from (15) is applied in the extraction of $C_{\mathrm{bci}}$ through (17). The extraction result of $C_{\mathrm{bci}}$ is used in the extraction of $C_{\text {bcx }}$ through (20).
TABLE I

Typical Results of the Proposed ACCURACY-IMPRovement PROCEDURE FOR THE $3 \times 0.34 \times 8 \mu \mathrm{m}^{2}$ SiGe AT $V_{\mathrm{BE}}=0.83 \mathrm{~V}$,

$\mathrm{V}_{\mathrm{CE}}=3 \mathrm{~V}, I_{B}=7.915 \mu \mathrm{A}$, AND $I_{C}=1.3328 \mathrm{~mA}$. THE Initial VALUE of $\left.R_{\mathrm{bi}}\right|_{L},\left.R_{\mathrm{bi}}\right|_{H}, C_{\mathrm{bci}}, \mathrm{AND} C_{\mathrm{bcx}}$ ARE $16.35 \Omega, 18.15 \Omega, 4.974 \mathrm{fF}$, AND $14.836 \mathrm{fF}$, RESPECTIVELY. THE EXTRACTED VALUE OF $R_{\mathrm{bi}} C_{\mathrm{bci}}, C_{\pi}$, AND $C_{\mathrm{bci}}+C_{\mathrm{bcx}}$ ARE $81.33 \mathrm{fs}, 330.57 \mathrm{fF}$, AND $19.81 \mathrm{fF}$, RESPECTIVELY

\begin{tabular}{c|c|c|c|c|c}
\hline $\begin{array}{c}\text { \# of } \\
\text { iteration }\end{array}$ & $\mathrm{R}_{\mathrm{bi} \mid \mathrm{L}}(\Omega)$ & $\mathrm{R}_{\mathrm{bi}} \mathrm{H}(\Omega)$ & $\mathrm{C}_{\mathrm{bci}}(\mathrm{fF})$ & $\mathrm{C}_{\mathrm{bcx}}(\mathrm{fF})$ & $\Delta \mathrm{R}_{\mathrm{bi}}(\Omega)$ \\
\hline 1 & 16.35 & 18.15 & 4.974 & 14.836 & 1.800 \\
\hline 2 & 17.828 & 17.881 & 4.562 & 15.248 & 0.0532 \\
\hline 3 & 17.872 & 17.903 & 4.551 & 15.259 & 0.0313 \\
\hline 4 & 17.873 & 17.904 & 4.55 & 15.26 & 0.0307 \\
\hline 5 & 17.873 & 17.904 & 4.55 & 15.26 & 0.0307 \\
\hline
\end{tabular}

2) The new lower and new upper limits of $R_{\mathrm{bi}}$ is obtained by taking the extracted $C_{\mathrm{bci}}$ and $C_{\mathrm{bcx}}$ in the calculation of (21) and (22), respectively.

$$
\begin{aligned}
\left.R_{\mathrm{bi}}\right|_{L}= & \frac{\left(C_{\mathrm{bci}}+C_{\pi}+C_{\mathrm{bcx}}\right)^{2}}{\left(C_{\mathrm{bci}}+C_{\pi}\right)^{2}} \\
& \times\left.\operatorname{Re}\left(\frac{A_{c, 12}}{A_{c, 22}}\right)\right|_{\text {at middle to high frequency }} . \\
\left.R_{\mathrm{bi}}\right|_{U}= & \left(1+\frac{C_{\mathrm{bci}}}{C_{\pi}}\right)^{-1} \\
& \times\left.\operatorname{Re}\left(\frac{A_{c, 12}}{\left|A_{c}\right|}\right)\right|_{\text {at middle to high frequency }} .
\end{aligned}
$$

The calculated $\left.R_{\mathrm{bi}}\right|_{L}$ is sent back to step 1) to repeat the calculation to step 2). Once the difference between $\left.R_{\mathrm{bi}}\right|_{L}$ and $\left.R_{\mathrm{bi}}\right|_{U}$ is minimum, $\left.R_{\mathrm{bi}}\right|_{L}$ is treated as the final $R_{\mathrm{bi}}$. A typical result of the proposed accuracy-improvement procedure for the $3 \times 0.34 \times 8 \mu \mathrm{m}^{2} \mathrm{SiGe}$ at $I_{B}=7.915 \mu \mathrm{A}, I_{C}=1.332 \mathrm{~mA}$, and $V_{\mathrm{CE}}=3.0 \mathrm{~V}$ is shown in Table I. The difference between $\left.R_{\mathrm{bi}}\right|_{L}$ and $\left.R_{\mathrm{bi}}\right|_{U}$ decreases very quickly in the first four iterations. The extracted $R_{\mathrm{bi}}, C_{\mathrm{bci}}$, and $C_{\mathrm{bcx}}$ are found to be $17.873 \Omega, 4.55 \mathrm{fF}$, and $15.26 \mathrm{fF}$, respectively.

\section{Extraction of $R_{\pi}, g_{m 0}$, and $\tau$}

The remaining unknowns are the intrinsic transconductance $g_{m 0}$, excess phase delay $\tau$, and base-emitter resistance $R_{\pi}$, which can be calculated as follows:

$$
\frac{1}{R_{\pi}}=\operatorname{Re}\left(\frac{A_{c, 11}\left|A_{c}\right|}{A_{c, 12}-\left|A_{c}\right| R_{\mathrm{bi}}}\right)
$$

The value of $R_{\pi}$ is estimated as $2.922 \mathrm{k} \Omega$ at $I_{B}=7.915 \mu \mathrm{A}$, $I_{C}=1.332 \mathrm{~mA}$, and $V_{\mathrm{CE}}=3.0 \mathrm{~V}$ for the $3 \times 0.34 \times 8 \mu \mathrm{m}^{2}$ SiGe HBT, as shown in Fig. 14. 


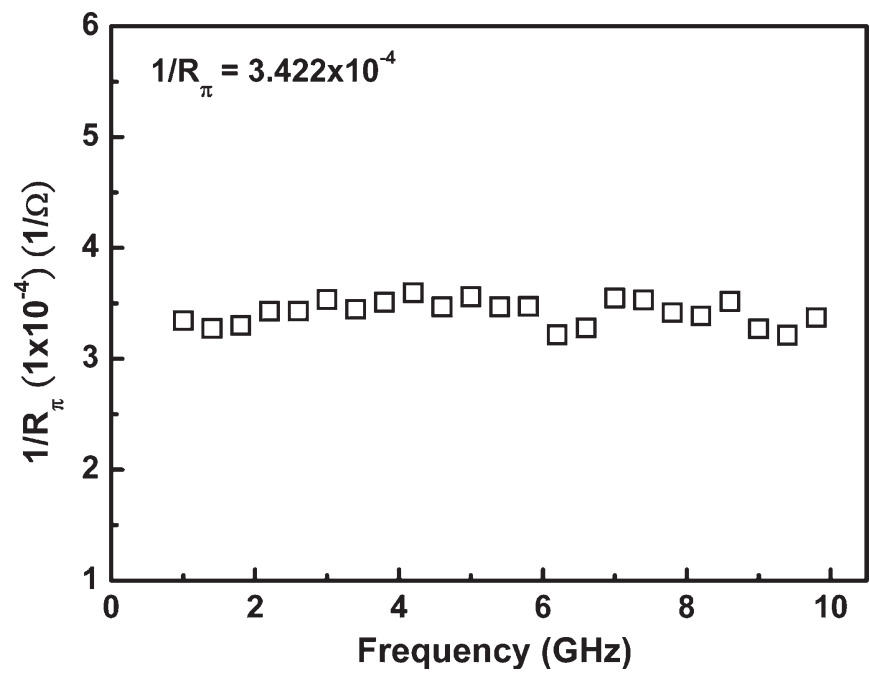

Fig. 14. Frequency dependence of the extracted $1 / R_{\pi}$ for a SiGe HBT biased at $V_{\mathrm{BE}}=0.83 \mathrm{~V}, V_{\mathrm{CE}}=3 \mathrm{~V}, I_{C}=1.333 \mathrm{~mA}$, and $I_{B}=7.915 \mu \mathrm{A}$.

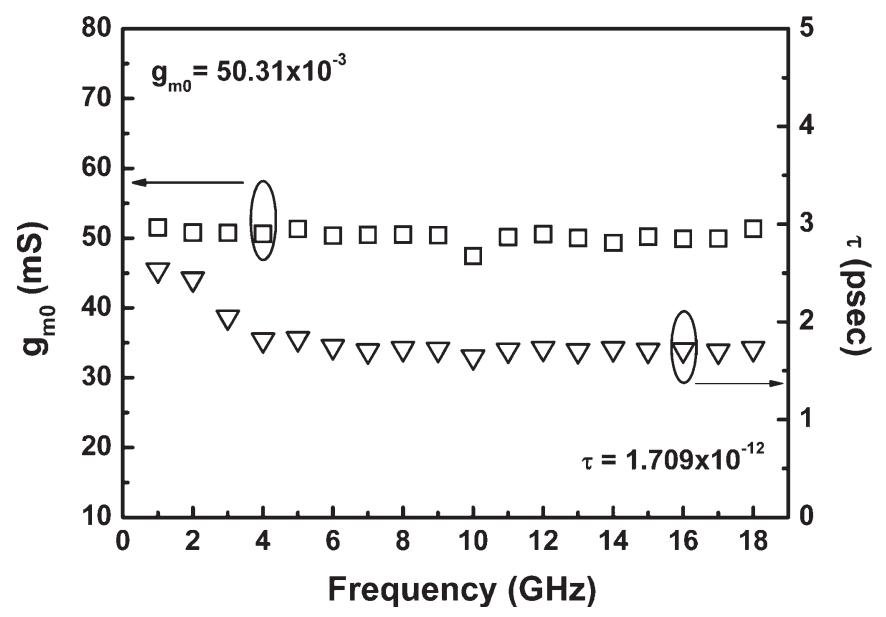

Fig. 15. Frequency dependence of the extracted $g_{m 0}$ and $\tau$ for a SiGe HBT biased at $V_{\mathrm{BE}}=0.83 \mathrm{~V}, V_{\mathrm{CE}}=3 \mathrm{~V}, I_{C}=1.333 \mathrm{~mA}$, and $I_{B}=7.915 \mu \mathrm{A}$.

The transconductance $g_{m 0}$ and the excess phase delay $\tau$ is calculated as follows:

$$
\begin{aligned}
g_{m} & =\frac{1-\left|A_{c}\right|}{\left|A_{c}\right|} Y_{\pi} \\
g_{m 0} & =\sqrt{\operatorname{Re}\left(g_{m}\right)^{2}+\operatorname{Im}\left(g_{m}\right)^{2}} \\
\tau & =-\tan ^{-1}\left(\frac{\operatorname{Im}\left(g_{m}\right)}{\operatorname{Re}\left(g_{m}\right)}\right) \times \frac{1}{\omega} .
\end{aligned}
$$

Fig. 15 shows the extracted results for the $3 \times 0.34 \times 8 \mu \mathrm{m}^{2}$ SiGe HBT biased at $I_{B}=7.915 \mu \mathrm{A}, I_{C}=1.332 \mathrm{~mA}$, and $V_{\mathrm{CE}}=3.0 \mathrm{~V}$. The extracted $g_{m 0}$ and $\tau$ are $50.31 \mathrm{mS}$ and $1.709 \mathrm{ps}$, respectively. Both $g_{m 0}$ and $\tau$ are found to be nearly constant in the desired frequency range.

\section{RESUlTS AND Discussion}

The proposed direct extraction method was applied to determine the parameters of the test devices, which were mul-

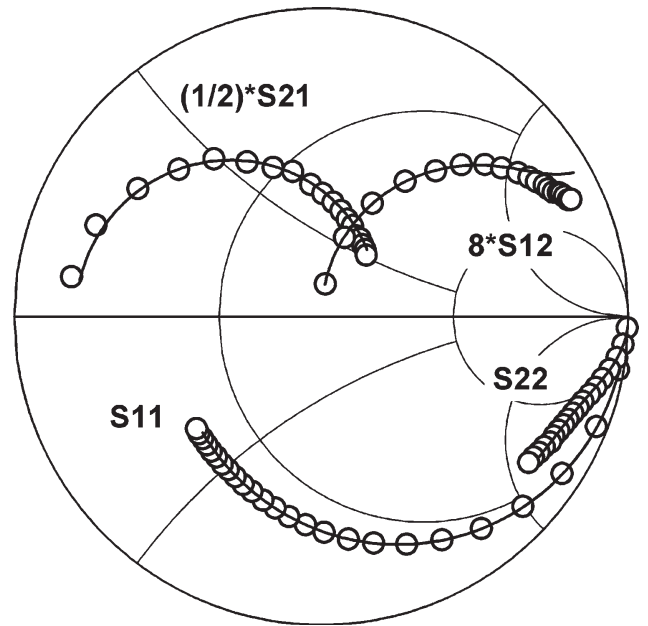

Fig. 16. Measured (symbol) and simulated (line) $S$-parameters of the $3 \times$ $0.34 \times 8 \mu \mathrm{m}^{2} \mathrm{SiGe}$ HBT in the frequency range of $1-30 \mathrm{GHz}$ at $V_{\mathrm{BE}}=0.8 \mathrm{~V}$, $V_{\mathrm{CE}}=2 \mathrm{~V}, I_{B}=2.477 \mu \mathrm{A}$, and $I_{C}=0.414 \mathrm{~mA}$.

tifingered SiGe HBTs fabricated by the $0.35-\mu \mathrm{m}$ BiCMOS technology [10]. The device under test (DUT) has three fingers, and the emitter's width and length are 0.34 and $8 \mu \mathrm{m}$, respectively. Typical cutoff frequency $\left(f_{T}\right)$ and maximum oscillation frequency $\left(f_{\max }\right)$ are about 23 and $40 \mathrm{GHz}$, respectively. $S$-parameters are measured in the common-emitter configuration using on-wafer RF probes and an HP $8510 \mathrm{C}$ vector network analyzer. The initial calibration was performed on a separate ceramic calibration substrate using a short-open-loadthru (SOLT) calibration method.

Fig. 16 shows the comparisons between the measured and calculated $S$-parameters for $V_{\mathrm{CE}}=2 \mathrm{~V}$ and $V_{\mathrm{BE}}=0.8 \mathrm{~V}$, which is the worst fit in the test bias conditions. Good agreements over the whole frequency range were obtained. Table II gives the small-signal model parameters' values for the extracted bias-dependent and bias-independent elements. The residual discrepancy calculated by the error function [7], [20] is $0.752 \%$. Therefore, we believe that the proposed method is an accurate extraction technique applicable to evaluate the process technology and optimize the transistor design.

\section{CONCLUSiON}

In this paper, an improved extraction technique for the small-signal modeling of SiGe HBTs is proposed. Being different from other methods, this technique considers the internal feedback signal through intrinsic circuit elements when extracting the substrate-network parameters. Without this, we may extract a negative effective substrate resistance in the large-area SiGe HBTs since the measured $\operatorname{Re}\left(Y_{22}+Y_{21}\right)$ is negative due to the interaction of intrinsic circuit elements. Transforming the intrinsic equivalent circuit into its commoncollector configuration, all the circuit elements are extracted directly without using any optimization. Two formulas of intrinsic base resistance $\left(R_{\mathrm{bi}}\right)$ are presented, which is followed by an accuracy-improvement procedure to obtain better accuracy of the intrinsic base-collector capacitance $\left(C_{\mathrm{bci}}\right)$ and extrinsic base-collector capacitance $\left(C_{\mathrm{bcx}}\right)$. Simplified formulas to 
TABLE II

EXTRACTED VALUES OF THE EQUiVALENT-CiRCUIT ElEMENTS

\begin{tabular}{|c|c|c|c|c|c|c|c|c|c|}
\hline $\mathrm{C}_{\text {bep }}(\mathrm{fF})$ & \multicolumn{2}{|c|}{$\mathrm{C}_{\mathrm{bcp}}(\mathrm{fF})$} & $\mathrm{R}_{\mathrm{e}}(\Omega)$ & $\mathrm{R}_{\mathrm{bx}}(\Omega)$ & $\mathrm{R}_{\mathrm{c}}(\Omega)$ & $\mathrm{L}_{\mathrm{e}}(\mathrm{pH})$ & \multicolumn{2}{|c|}{$\mathrm{L}_{\mathrm{b}}(\mathrm{pH})$} & $\mathrm{L}_{\mathrm{c}}(\mathrm{pH})$ \\
\hline 22.9 & \multicolumn{2}{|l|}{0} & 1.671 & 2 & 3 & 8.108 & \multicolumn{2}{|c|}{9.42} & 6.802 \\
\hline $\begin{array}{l}\mathrm{R}_{\mathrm{bi}} \\
(\Omega)\end{array}$ & $\begin{array}{l}\mathrm{C}_{\mathrm{bci}} \\
(\mathrm{fF})\end{array}$ & $\begin{array}{l}C_{b c x} \\
(f F)\end{array}$ & $\begin{array}{c}\mathrm{C}_{\pi} \\
(\mathrm{fF})\end{array}$ & $\begin{array}{c}\mathrm{R}_{\pi} \\
(\mathrm{k} \Omega)\end{array}$ & & $\begin{array}{c}\tau \\
(\mathrm{psec})\end{array}$ & $\begin{array}{l}\mathrm{C}_{\text {sub }} \\
(\mathrm{fF})\end{array}$ & $\begin{array}{l}\mathrm{C}_{\mathrm{bk}} \\
(\mathrm{fF})\end{array}$ & $\begin{array}{l}\mathrm{R}_{\mathrm{bk}} \\
(\Omega)\end{array}$ \\
\hline .33 & 4.363 & 16.65 & 221.1 & 10.27 & 16.57 & 1.859 & 15.82 & 28.98 & 179.4 \\
\hline
\end{tabular}

determine the base-emitter resistance $\left(R_{\pi}\right)$, base-emitter capacitance $\left(C_{\pi}\right)$, transconductance $\left(g_{m}\right)$, and excess phase delay $(\tau)$ are presented. The measured and calculated $S$-parameters have an excellent agreement with below $1 \%$ discrepancy in the frequency range of $1-30 \mathrm{GHz}$ over a wide range of bias points.

\section{REFERENCES}

[1] G. L. Patton, D. L. Harame, J. M. C. Stork, B. S. Meyerson, G. J. Scilla, and E. Ganin, "SiGe-base, poly-emitter heterojunction bipolar transistors," in VLSI Symp. Tech. Dig., 1989, pp. 35-36.

[2] M. Case, S. A. Maas, L. Larson, D. Rensch, D. Harame, and B. Meyerson, "An X-band monolithic active mixer in SiGe HBT technology," in Proc. IEEE MTT-S Dig., 1996, pp. 655-658.

[3] J. S. Rieh, L. H. Lu, L. P. B. Katehi, P. Bhattacharya, E. T. Croke, G. E. Ponchak, and S. A. Alterovitz, "X- and Ku-band amplifiers based on Si/SiGe HBT's and micromachined lumped components," IEEE Trans. Microw. Theory Tech., vol. 46, no. 5, pp. 685-694, May 1998.

[4] T. K. Johansen, J. Vidkjær, and V. Krozer, "Substrate effects in SiGe HBT modeling," in Proc. GAAS Conf., 2003, pp. 445-448.

[5] T. H. Teo, Y. Z. Xiong, J. S. Fu, H. Liao, J. Shi, M. Yu, and W. Li, "Systematic direct parameter extraction with substrate network of SiGe HBT," in Proc. RFIC Conf., 2004, pp. 603-606.

[6] U. Basaran, N. Wieser, G. Feiler, and M. Berroth, "Small-signal and highfrequency noise modeling of SiGe HBTs," IEEE Trans. Microw. Theory Tech., vol. 53, no. 3, pp. 919-928, Mar. 2005.

[7] K. Lee, K. Choi, S.-H. Kook, D.-H. Cho, K.-W. Park, and B. Kim, "Direct parameter extraction of SiGe HBTs for the VBIC bipolar compact model," IEEE Trans. Electron Devices, vol. 52, no. 3, pp. 375-384, Mar. 2005.

[8] F. Lenk and M. Rudolph, "New extraction algorithm for GaAs-HBTs with low intrinsic base resistance," in Proc. IEEE MTT-S Int. Dig., Jun. 2002, pp. $725-728$.

[9] H.-Y. Chen, K.-M. Chen, G.-W. Huang, and C.-Y. Chang, "A novel approach for parameter determination of HBT small-signal equivalent circuit," IEICE Trans. Electron., vol. E88-C, no. 6, pp. 1133-1141, Jun. 2005.

[10] K.-M. Chen, A.-S. Peng, G.-W. Huang, H.-Y. Chen, S.-Y. Huang, C.-Y. Chang, H.-C. Tseng, T.-L. Hsu, and V. Liang, "Linearity and power characteristics of SiGe HBTs at high temperatures for RF applications," IEEE Trans. Electron Devices, vol. 52, no. 7, pp. 1452-1458, Jul. 2005.

[11] S. Lee, C. S. Kim, and H. K. Yu, "A small-signal RF model and its parameter extraction for substrate effects in RF MOSFETs," IEEE Trans. Electron Devices, vol. 48, no. 7, pp. 1374-1379, Jul. 2001.

[12] C. J. Wei and J. C. M. Hwang, "Direct extraction of equivalent circuit parameters for heterojunction bipolar transistors," IEEE Trans. Microw. Theory Tech., vol. 43, no. 9, pp. 2035-2040, Sep. 1995.

[13] Y. Gobert, P. J. Tasker, and K. H. Bachem, "A physical, yet simple, smallsignal equivalent circuit for the heterojunction bipolar transistor," IEEE Trans. Microw. Theory Tech., vol. 45, no. 1, pp. 149-153, Jan. 1997.

[14] B. Li, S. Prasad, L. W. Yang, and S. C. Wang, "A semianalytical parameter-extraction procedure for HBT equivalent circuit," IEEE Trans. Microw. Theory Tech., vol. 46, no. 10, pp. 1427-1435, Oct. 1998.

[15] U. Basaran and M. Berroth, "High frequency noise modeling of SiGe HBTs using direct parameter extraction technique," in Proc. EDMO, 2002, pp. 189-195.

[16] B. Ardouin, T. Zimmer, H. Mnif, and P. Fouillat, "Direct method for bipolar base-emitter and base-collector capacitance splitting using high frequency measurements," in Proc. BCTM, 2001, pp. 114-117.

[17] U. Basaran and M. Berroth, "An accurate method to determine the substrate network elements and base resistance," in Proc. BCTM, 2003, pp. 93-96.
[18] S. Bousnina, P. Mandeville, A. B. Kouki, R. Surridge, and F. M. Ghannouchi, "Direct parameter-extraction method for HBT small-signal model," IEEE Trans. Microw. Theory Tech., vol. 50, no. 2, pp. 529-536, Feb. 2002.

[19] B. Sheinman, E. Wasige, M. Rudolph, R. Doerner, V. Sidorov, S. Cohen, and D. Ritter, "A peeling algorithm for extraction of the HBT small-signal equivalent circuit," IEEE Trans. Microw. Theory Tech., vol. 50, no. 12, pp. 2804-2810, Dec. 2002.

[20] I. Kwon, M. Je, K. Lee, and H. Shin, "A simple and analytical parameterextraction method of a microwave MOSFET," IEEE Trans. Microw. Theory Tech., vol. 50, no. 6, pp. 1503-1509, Jun. 2002.

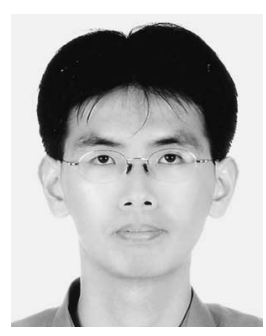

Han-Yu Chen received the B.S. degrees in electrical engineering from National Sun Yet-Sen University, Kaohsiung, Taiwan, R.O.C., in 2000. He is currently working toward a Ph.D. degree at the National Chiao Tung University (NCTU), Hsinchu, Taiwan, R.O.C.

His research interests include microwave device process and characterization.

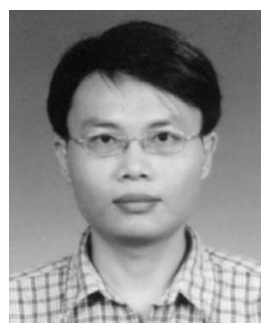

Kun-Ming Chen received the M.S. and the Ph.D. degrees in electronics engineering from National Chiao Tung University (NCTU), Hsinchu, Taiwan, R.O.C., in 1996 and 2000, respectively.

In 2000, he joined the National Nano Device Laboratories, Hsinchu, Taiwan, R.O.C., as an Associate Researcher. He was engaged in the research on the microwave device process and characterization.

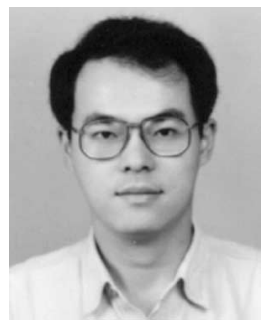

Guo-Wei Huang (S'94-M'97) received the B.S. degree in electronics engineering and the $\mathrm{Ph} . \mathrm{D}$. degree both from National Chiao Tung University (NCTU), Hsinchu, Taiwan, R.O.C., in 1991 and 1997, respectively.

In 1997, he joined the National Nano Device Laboratories, Hsinchu, Taiwan, R.O.C., as an Associate Researcher and became a Researcher in 2004. His current research interests focus on microwave device design, characterization, and modeling. 


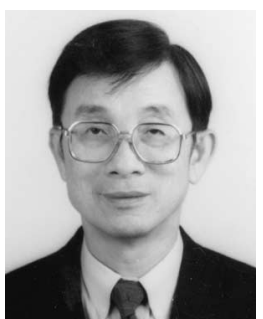

Chun-Yen Chang (S'69-M'70-SM'81-F'88LF'05) received the B.S. degree in electrical engineering from Cheng Kung University, Taiwan, R.O.C., and the M.S. degree in tunneling in semiconductor-superconductor junctions and the $\mathrm{Ph} . \mathrm{D}$. degree in carrier transport across metalsemiconductor barrier both from National Chiao Tung University (NCTU), Hsinchu, Taiwan, R.O.C., in 1960 and 1969 , respectively.

He has devoted himself to education and academic research for more than 40 years. He has contributed profoundly to the areas of microelectronics and optoelectronics, including the invention of the method of low-pressure MOCVD using tri-ethyl-gallium to fabricate LED, laser, and microwave transistors, $\mathrm{Zn}$ incorporation of $\mathrm{SiO}_{2}$ for stabilization of power devices, and nitridation of $\mathrm{SiO}_{2}$ for ultralarge-scale integrations (ULSIs), etc. From 1962 to 1963, he fulfilled his military service by establishing at NCTU Taiwan's first experiment TV transmitter that formed the founding structure of today's cable television services (CTS). In 1963, he joined NCTU as an Instructor, establishing a high-vacuum laboratory. In 1964, he and his colleague established the semiconductor research center (SRC) at NCTU with a very up-to-date, albeit homemade, facility for silicon device processing, where they made the nation's first Si planar transistor in April 1965 and, subsequently, the first IC in August 1966. In 1968, he published
Taiwan's first-ever semiconductor paper in the international journal Solid State Electronics. In 1969, he became a Full Professor, teaching solid state physics, quantum mechanics, and semiconductor devices and technologies. From 1977 to 1987 , he single-handedly established a strong electrical engineering and computer science program at National Cheng Kung University (NCKU), where GaAs, $\alpha$-Si, and poly-Si researches were established in Taiwan for the first time. He served consecutively as the Dean of Research (1987-1990), the Dean of Engineering (1990-1994), and the Dean of Electrical Engineering and Computer Science (1994-1995). Simultaneously, he was serving as the Founding President of National Nano Device Laboratories (NDL) from 1990 to 1997. In 1997, he became the Director of the Microelectronics and Information System Research Center (MIRC), NCTU (1997-1998). Many of his former students have since become founders of the most influential hi-tech enterprises in Taiwan, R.O.C., namely UMC, TSMC, Winbond, MOSEL, Acer, Leo, etc. On August 1, 1998, he was appointed as the President of NCTU. As the National-Chair-Professor and President of NCTU, his vision is to lead the university for excellence in engineering, humanity, art, science, management, and biotechnology. To strive forward to become a world-class multidisciplinary university is the main goal to which he and his colleagues have committed.

Dr. Chang received the IEEE third millennium medal in 2000 . He is a member of the Academia Sinica and a Foreign Associate of the National Academy of Engineering. 